\title{
AGE AND POPULATION STRUCTURE OF JOSHUA TREES (YUCCA BREVIFOLIA) IN THE NORTHWESTERN MOJAVE DESERT
}

\author{
Kimberly D. Gilliland ${ }^{1}$, Nancy J. Huntly ${ }^{1,2}$, and J.E. Anderson ${ }^{1,3}$
}

\begin{abstract}
Many desert perennials are long-lived, but there are few data on ages or population structures of desert plants. We used 2 methods to estimate ages of a population of Yucca brevifolia (Joshua tree) in southwestern Utah from a 14-year census of plant sizes. Plant height at the 1st census ranged from $0.08 \mathrm{~m}$ to $6.0 \mathrm{~m}$, and trees grew in height at a mean rate of $3.75 \mathrm{~cm} \cdot \mathrm{yr}^{-1}$. Plants also increased slowly in basal diameter $\left(0.142 \mathrm{~cm} \cdot \mathrm{yr}^{-1}\right)$ and branch length $(0.024 \mathrm{~m}$. $\left.\mathrm{yr}^{-1}\right)$, but basal diameter varied greatly from year to year, with many plants decreasing in diameter between sequential censuses. Forms of a nonlinear growth equation (the Richards function) did not fit the data on growth in height, but a simple linear relationship fit the data well. Using height as a linear predictor of age, we estimated that ages of a sample of 69 Joshua trees ranged from $<20$ to $>300$ years old, with $75 \%$ of the trees between 20 and 100 years and $11 \%$ over 150 years old. These data support the assumption that Joshua trees are indeed long-lived.
\end{abstract}

Key words: Yucca brevifolia, Joshua tree, age, growth rate, population structure, Mojave Desert, demography.

Joshua trees (Yucca brevifolia) are woody monocots found exclusively in the Mojave Desert of the southwestern United States at elevations ranging from $700 \mathrm{~m}$ to $2100 \mathrm{~m}$ (Rowlands 1978). They have been reported to grow to heights of $15 \mathrm{~m}$ (Smith et al. 1983), although heights of 6-9 $\mathrm{m}$ are more common (McKelvey 1935). Reported rates of growth in height range from $1.5 \mathrm{~cm} \cdot \mathrm{yr}^{-1}$ to $10 \mathrm{~cm} \cdot \mathrm{yr}^{-1}$ (Rowlands 1978, Comanor and Clark 2000). Determination of age is difficult because $Y$. brevifolia does not produce the annual xylem rings that are commonly used to age dicots.

Studies of other desert perennials have shown that age can be estimated from longterm census data that include plant sizes (Shreve 1910, Steenbergh and Lowe 1977, Humphrey and Humphrey 1990, Turner 1990, Pierson and Turner 1998, Cody 2000). Historical photographs also have been used to study growth of individuals and change in population structure (Turner 1990, Bowers et al. 1995, Wondzell and Ludwig 1995), and age has been estimated coarsely for areas that have been disturbed, assuming that the largest plants can be no older than the date of the disturbance (Bowers and Turner 2001). Drezner (2003) used repeated measures of the heights of saguaro (from Steenburgh and Lowe 1983) to calculate a relative growth relationship that could be extended to other populations by addition of a site-specific scaling factor.

We estimated growth rates and inferred the age structure of a population of $Y$. brevifolia that was sampled at 2-year intervals from 1987 through 2001. We used height as a predictor of age, because height is easily measured and repeatable in the field. If growth of $Y$. brevifolia is consistently related to plant height, age can be estimated from height measurements (Humphrey and Humphrey 1990).

\section{STUdy SiTE}

We studied a Joshua tree forest at Lytle Preserve $\left(37^{\circ} 9^{\prime} \mathrm{N}, 114^{\circ} 1^{\prime} \mathrm{W}\right), 48 \mathrm{~km}$ west of St. George, Utah, at $850 \mathrm{~m}$ elevation in the northeastern Mojave Desert. The nearest weather station is at St. George, where average annual temperature is $16.5^{\circ} \mathrm{C}$ and average precipitation is $210 \mathrm{~mm} \cdot$ year $^{-1}$.

We sampled Yucca brevifolia on 2 adjacent benches east of the Beaver Dam Wash, a tributary of the Virgin River that runs through the Lytle Preserve. Other common plant species on the benches included Coleogyne ramosissima (blackbrush, 42.83\% cover based on lineintercept sampling), Thamnosma montana (turpentine bush, $12.37 \%$ cover), Krameria grayi (white ratany, $12.20 \%$ cover), Ambrosia dumosa

\footnotetext{
${ }^{1}$ Department of Biological Sciences, Idaho State University, Pocatello, ID 83209-8007.

${ }^{2}$ Corresponding author

${ }^{3}$ Deceased.
} 
(burroweed, 9.16\% cover), and Larrea tridentata (creosote bush, $7.91 \%$ cover).

Yucca brevifolia are the tallest plants on the benches, and they provide shade and habitat for other organisms (Webber, 1953, unpublished data). Despite their sharply tipped and serrated leaves, birds, insects, and lizards depend on them for cover. Neotoma lepida (desert woodrats) build their middens at the base of individual trees and also harvest and eat the leaves (Lee, 1963, unpublished data).

\section{Methods}

We analyzed data from 1987 to 2001 for 77 trees. In 1987 we sampled the Y. brevifolia population, using the point-quarter method, from three 120-m transects on each of 2 benches at Lytle Preserve. We selected and tagged the nearest tree in the 4th quadrant at every $30-\mathrm{m}$ point on each transect, resulting in 46 trees that we subsequently remeasured over 14 years. In 1988 we also tagged and measured every tree between 2 transect lines, forming a belt transect and adding 31 additional trees to the sample. During the 14 years of our study, 7 point-quarter trees and 1 belt-transect tree died. Only the surviving 39 point-quarter trees, which constituted a random sample of the population, were used to estimate the growthheight relationship over the 14 years, but we estimated ages for all 69 surviving trees from both samples. We also calculated the age to which $50 \%$ of individuals survived and the oldest age reached by $5 \%$ of the population from the per capita annual survival probability, using methods in Cody (2000).

We measured each tagged tree's height, diameter, and number of branches in the springs of 1987-1989, 1991, 1993, 1995, 1999, and 2001. We measured height from the ground to the top of the tallest branch to the nearest 1 $\mathrm{cm}$ using a stadia rod; measured diameter to the nearest $1 \mathrm{~cm}$ at the base of the trunk just above the basal swell using calipers for smaller trees and a DBH tape for larger trees; and counted branches on each tree 3 times and recorded the average of those counts as branch number.

We also measured rates of growth of photosynthetic leaf whorls (branch growth) for each tree. Branches of $Y$. brevifolia end in a whorl of leaves, with the youngest leaves forming at the terminal tip of the branch. As the leaves mature and become less photosynthetically active, they yellow and reflex (Rasmuson et al. 1994). We tagged 3 accessible branches on each tree (unless a tree had fewer branches, in which case all were tagged) at the base of the photosynthetic (green) portion of the terminal leaf whorl. We estimated branch growth as the difference between the lengths from the tag to the tip in 2001 and in 1987.

We estimated age for each tree by calculating the linear relationship of height as a function of time and extrapolating this relationship backwards to estimate the time at which a tree was height 0 and assumed to be age 0 . We regressed tree height against time (years) and estimated the growth rate in height $\left(\mathrm{m} \cdot \mathrm{yr}^{-1}\right)$ for each tree as the slope of the best-fit line. The $\mathrm{x}$-intercept of this relationship is the best estimate of the year of germination of a tree. We also calculated a general, population-wide equation for age of a tree of a given height using the mean growth rate of all trees in the sample.

We also attempted to estimate age with the Richards equation, which is an asymptotic function often used to model ontogenetic growth when growth is well described by a saturating function (i.e., when height or another measure of size increases to an asymptote as organisms grow to maximum adult size; Ebert 1999). The Richards function

$$
S_{t}=S_{\infty}\left(1-b \cdot e^{-k t}\right)^{-n}
$$

requires estimation of 4 parameters: $t$, time; $b$, the intercept of the relationship of height at age $t ; k$, the growth rate constant; $n$, a parameter that scales the shape of the growth curve; and $S_{\infty}$, the asymptotic maximum height. We regressed height in 2001 against height in 1991 to obtain the slope, which we used to estimate $k$, and the intercept, used to estimate $b$. The shape parameter, $n$, was determined by the relationship

$$
n=-\ln \left(S_{\infty}\right) \cdot[\ln (b /(1-k))]^{-1}
$$

Using these parameter estimates, age of each tree at each sample was estimated by solving the equation,

$$
\operatorname{age}(t)=(-1 / k) \cdot \ln \left(1-S_{t} / S_{\infty}\right)^{-1 / n}
$$

There is not a unique solution for $n$ and $k$, so we explored effects of using a range of possible 


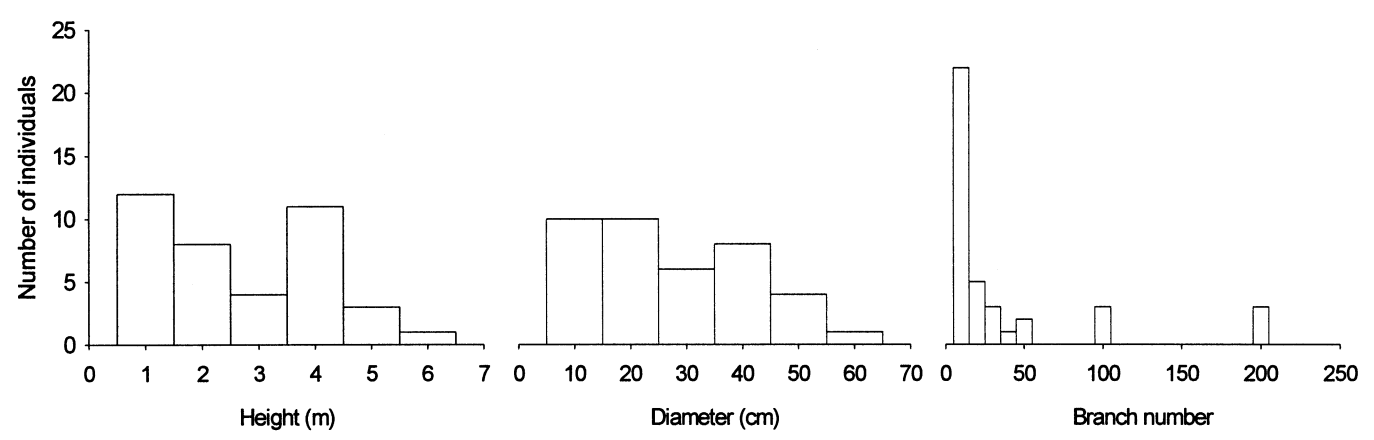

Fig.1. Frequency distributions of height, basal diameter, and number of branches for 45 Yucca brevifolia at Lytle Preserve, Utah, in 1987.

solutions for these 2 parameters. We also explored the effects of using a range of maximum plant heights, 4-30 m. Larger values fit the data better, but were unreasonably large for the population (maximum observed height $=$ $5.58 \mathrm{~m}$ ) or species. The $95 \%$ confidence intervals for $n$ and $k$ did not give a reasonable combined confidence interval around the final height-age relationship; in fact, the calculated confidence intervals failed to contain the estimated growth curve. Thus, we concluded that the Richards equation was not a good descriptor of the ontogenetic growth curve for $Y$. brevifolia.

\section{RESUlts}

In 1987 the sample of $Y$. brevifolia from the Lytle Preserve ranged from single-stemmed trees a few centimeters in height to trees approximately $6 \mathrm{~m}$ in height having nearly 200 branches (Fig. 1). The lengths of individual branches also varied widely, the shortest being only a few centimeters and the longest $2 \mathrm{~m}$.

Over the 14 years of the study, Y. brevifolia increased in height, but decreased in diameter. In 1987 heights of $Y$. brevifolia in the point-quarter sample ranged from $0.14 \mathrm{~m}$ to $5.12 \mathrm{~m}(\bar{x}=2.20 \mathrm{~m})$, whereas in 2001 the range was $0.50 \mathrm{~m}$ to $5.58 \mathrm{~m}(\bar{x}=2.73 \mathrm{~m})$. Basal diameter varied erratically between years, but height and diameter nevertheless were strongly linearly related (2001 data: $\mathrm{y}=8.05 \mathrm{x}+1.897$, $\left.r^{2}=0.832, \mathrm{df}=68, P<0.001\right)$.

The number of branches also was positively correlated with height (2001 data: $r=0.689, P$ $<0.001, n=69$ ), and changed little overall between 1988 and 2001, ranging from 1 to 192 branches per tree in 1987 (Fig. 1) and from 1 to 189 in 2001. The change in branch length between 1987 and 2001 ranged from $0 \mathrm{~m}$ to $2.89 \mathrm{~m}\left(\bar{x}=0.336 \mathrm{~m}, s_{\bar{x}}=0.10\right)$, giving an estimated annual growth rate of $0.024 \mathrm{~m} \cdot \mathrm{yr}^{-1}$. Growth in height and in branch length were only weakly and insignificantly correlated ( $\rho$ $=0.164, n=36, P=0.340$ ), which suggests that branch growth does not significantly slow growth in height.

The changes in heights of trees over time were well predicted by a linear relationship, with all but 3 of the point-quarter trees and all but 1 of the belt trees having significant linear relationships of height with time, and with most of these explaining high proportions of the total variation in height over time. The mean estimated equation for the point-quarter trees was height $(\mathrm{m})=2.092+0.037$ years from 1987, with slopes (growth rates) ranging from 0.013 to 0.080 . The lowest $r^{2}$ value was 0.572 and $83 \%$ of the equations had an $r^{2}$ greater than 0.70 . The mean equation for the belt transect trees was $\mathrm{y}=0.816+0.036 \mathrm{x}$, with slopes ranging from 0.011 to $0.085 ; 96 \%$ of the equations had $r^{2}$ values greater than 0.70 , with none $<0.665$.

The overall relationship between heights of trees in 1988 and 2001 also was well fit by a line (point-quarter trees: $\mathrm{y}=0.444+0.959 \mathrm{x}$, $r^{2}=0.903, \mathrm{df}=38, P<0.001$; belt trees: $\mathrm{y}=$ $1.176 \mathrm{x}+0.249, r^{2}=0.869, \mathrm{df}=29, P<0.001$; all trees combined: Fig. 2a); and the relationship between growth rates of trees between 1988 and 2001 and their heights in 1988 was only slightly negative, explained $<1 \%$ of the variation in growth rate, and was not statistically significant (Fig. 2b). Similarly, growth rates 


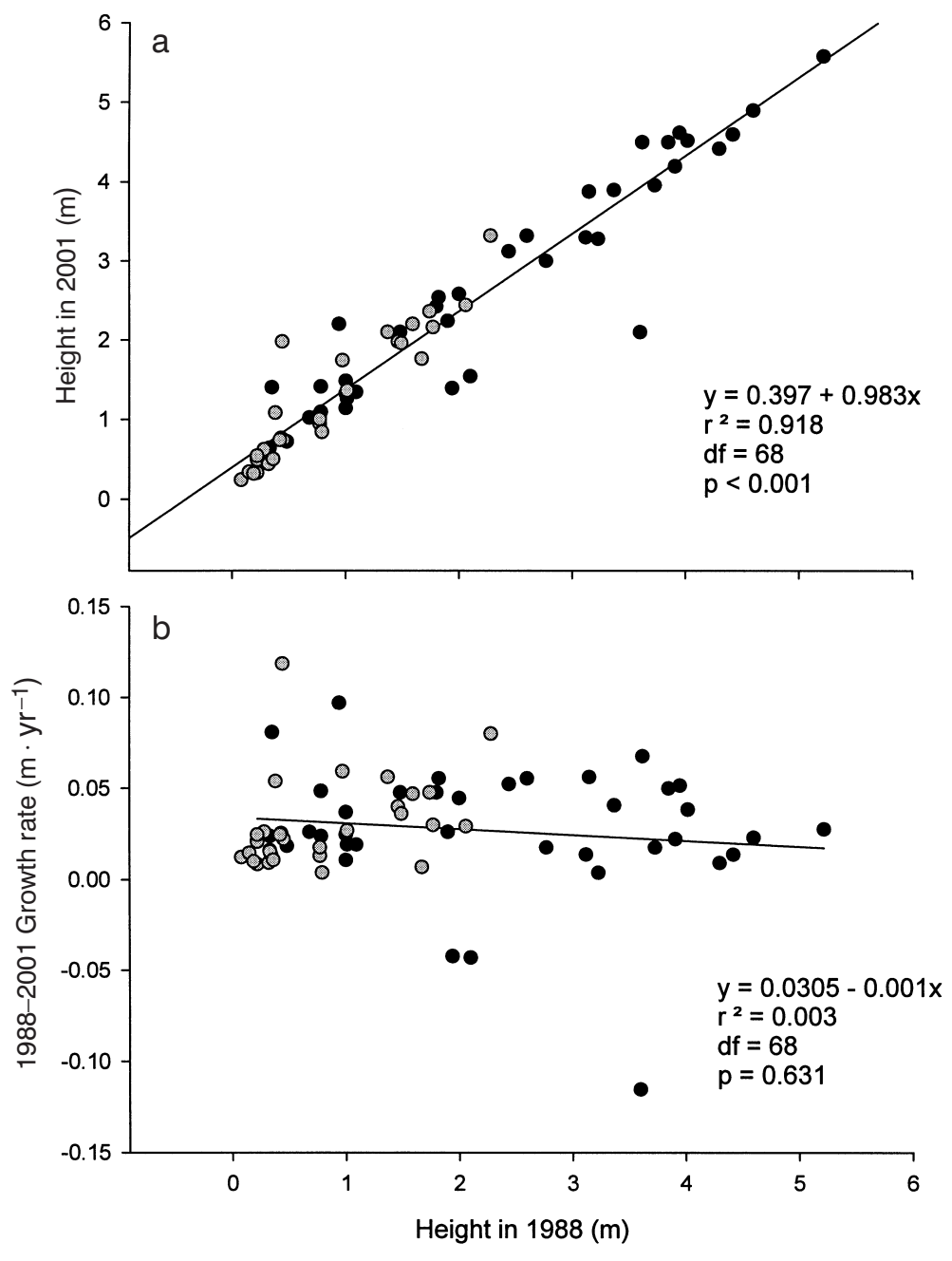

Fig. 2. (a) Height in 2001 as a function of height in 1988, and (b) growth rate as a function of height in 1988, for Yucca brevifolia sampled at Lytle Preserve, Utah. Point-quarter trees $(n=39)$ are in black, and belt transect trees $(n=30)$ are in gray.

of point-quarter trees from 1988 to 2001 decreased only slightly with tree height, and the relationship was not statistically significant $(\mathrm{y}$ $=0.341-0.003 \mathrm{x}, r^{2}=0.017, \mathrm{df}=38, P=$ 0.428). Growth rates of the belt-transect trees, which were smaller on average, did increase slightly with tree size $\left(\mathrm{y}=0.0192+0.135 \mathrm{x}, r^{2}\right.$ $=0.129, \mathrm{df}=29, P=0.052)$; however, the mean growth rates of the point-quarter trees $\left(0.0375 \mathrm{~m} \cdot \mathrm{yr}^{-1}\right)$ and belt transect trees $(0.0363$ $\left.\mathrm{m} \cdot \mathrm{yr}^{-1}\right)$ did not differ significantly (2-sample $t$ test: $t=0.194$, df $=39, P=0.846)$, and both were within the range reported for $Y$. brevifolia (Rowlands 1978).
Overall, the average growth rate of trees varied little among the five 2-year intervals we examined (Fig. 3a; ANOVA: $F=2.506$, df $=$ 3,152, $P=0.062$ ), being slightly higher from 1987 to 1989 and 1999 to 2001 than over other intervals. However, trees differed in temporal growth patterns (Fig. 3b). For instance, some trees grew fastest between 1999 and 2001, but others grew slowest over that interval.

Tree age, estimated for each individual from its own growth rate, ranged from 16 to 321 years, with the point-quarter trees averaging 79.7 years old and the belt transect trees averaging 39.2 years old (Fig. 4a). This method of 

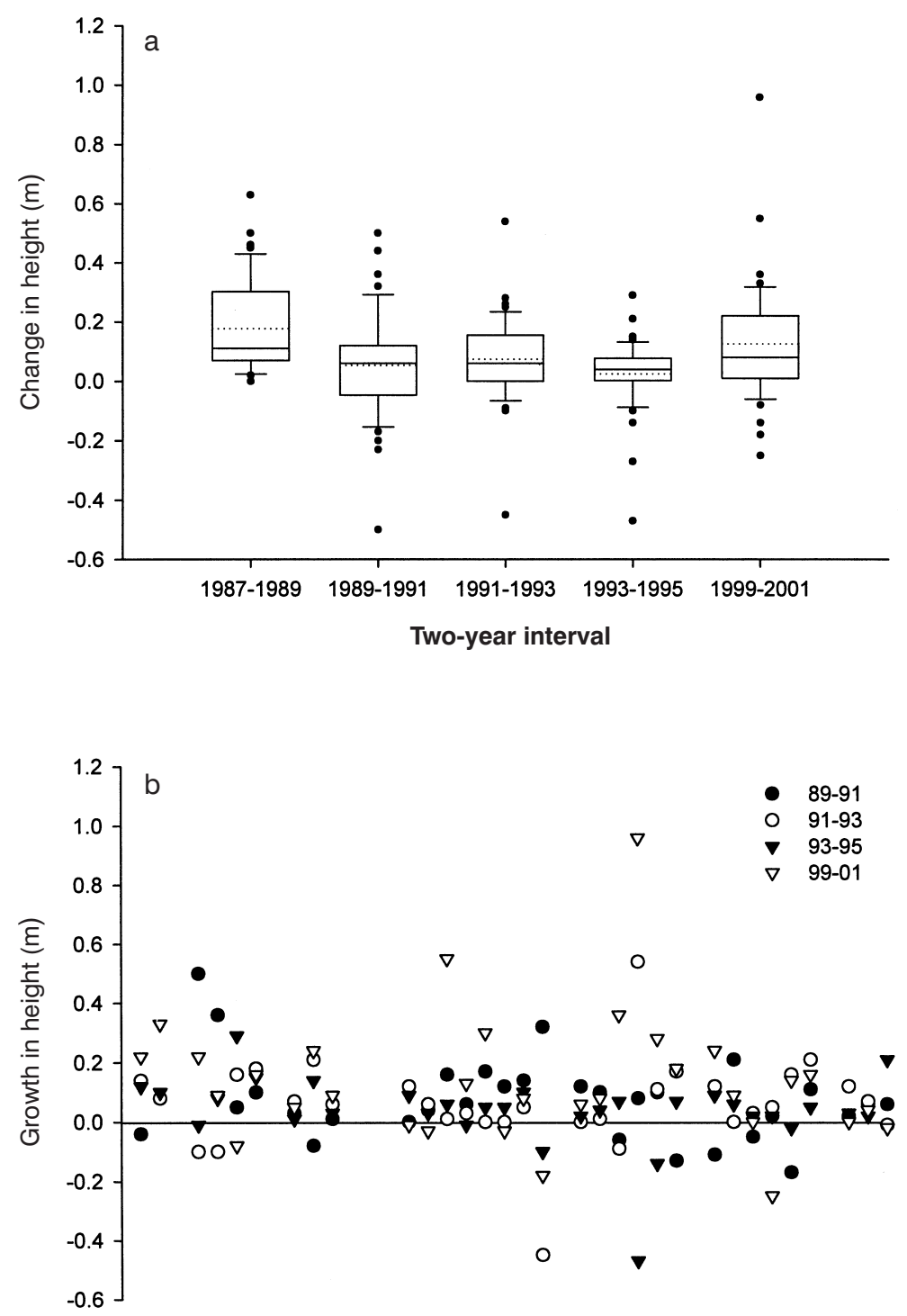

Individual Y. brevifolia

Fig. 3. (a) Box plots showing change in height of 39 point-quarter trees for each of five 2 -year intervals; the dotted line represents the mean. (b) Growth in height of each tree for each time period; each column of points represents 1 tree.

aging indicated that $\sim 75 \%$ of trees were between 20 and 100 years old, but $11 \%$ were $>150$ years old in 1987 (Fig. 4a). The average growth rate for the sampled population $(0.0375$ $\mathrm{m} \cdot \mathrm{yr}^{-1}$ ) gave more conservative estimates of age, with trees estimated to range from 2.2 to 138.4 years old in 1987 (Fig. 4b).

The annual per capita survival probability for the population from 1987 to 2001 was 0.896 , and the annual survival was 0.992 . These values predict that $50 \%$ of individuals survive to 89 years old and that the oldest age reached by $5 \%$ of the population would be 383 years.

\section{Discussion}

The population of $Y$. brevifolia at Lytle Preserve, Utah, clearly has a long maximum life span and includes substantial numbers of very old trees. The population also has a high proportion of relatively young trees, indicating recent establishment of Joshua trees (Fig. 4). 

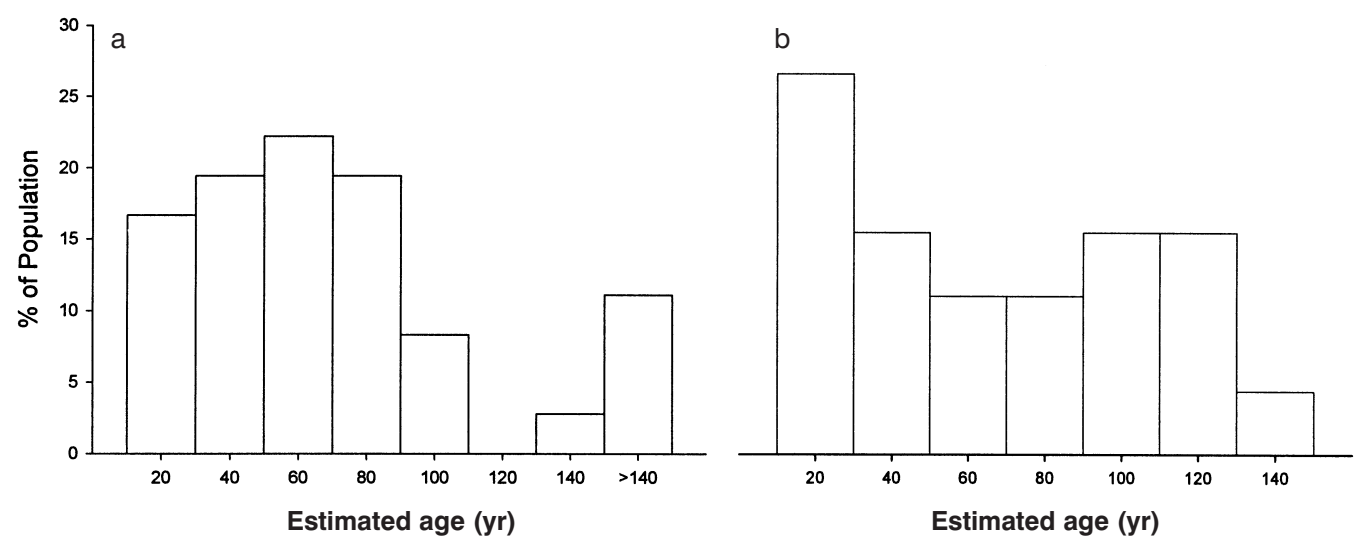

Fig. 4. Distribution of ages for a population of Y. brevifolia at Lytle Preserve, Utah, in 1987 as estimated from (a) individual growth rates and (b) average growth rate of the population.

The oldest trees were estimated to be $>300$ years old based on each tree's growth rate; the more conservative estimates of age that were based on the average growth-size relationship for the population suggest a considerably lower maximum age of 138 years. These 2 estimates of tree ages provide bounds on the likely true ages. Estimates calculated from each tree's growth rate incorporate the observed tree-totree variation in growth, whereas those based on the population's average growth rate ignore local variation in growth rate and are more conservative. Both approaches indicate that Joshua trees at Lytle Preserve are long-lived, that they have established frequently over the past century, and that the population has recruited young trees recently.

Estimates of demography based on observed patterns of survivorship support similar conclusions about longevity. The estimated median life expectancy of 89 years, as well as the relatively old age (383 years) that $5 \%$ of the population is estimated to reach, indicate that Joshua trees are long-lived.

The estimated mean rate of growth in height was $3.7 \mathrm{~cm} \cdot \mathrm{yr}^{-1}$, similar to the $4 \mathrm{~cm} \cdot \mathrm{yr}^{-1}$ reported by Comanor and Clark (2000); and the maximum ( 321 years) and mean (62.2 years) estimated ages of trees at Lytle Preserve were comparable to ages estimated for other desert perennials. For instance, some Idria columnaris live as long as 342 years, and Carnegeia gigantea live an average of 125-175 years (Humphrey and Humphrey 1990, Pierson and Turner 1998). Thus, both direct estimation of ages from growth rates and indirect estimation of ages indicate that $Y$. brevifolia must be regarded as having moderately frequent establishment and life spans of 1 to several centuries.

Height, which increased quite steadily and linearly during the 14 years of our study (Fig. 2a), was more useful in predicting ages of Y. brevifolia than branch number or basal diameter, both of which fluctuated significantly between censuses. Yucca brevifolia often branch at the site of an inflorescence (Smith et al. 1983), and trees flowered several times during the study. Branches also formed independently of flowering, and many trees added branches during the study. Many trees also lost branches that had died and detached. Although basal diameter would seem to be a good indicator of age, basal diameters of trees increased as much as $4.8 \mathrm{~cm}$ and decreased as much as $7.9 \mathrm{~cm}$ between sequential censuses, making this metric a poor and unstable indicator of age, at least over the relatively short time span we sampled. The fluctuation in basal diameter between years was most likely due to changes in water content of trees, which apparently shrink during drought and expand when water is more plentiful (Phillips et al. 1980).

We had expected the Richards equation, which describes well the growth of some desert plants such as C. gigantea (Ebert 1999), to model growth of $Y$. brevifolia, which we expected to show a saturating pattern of growth. Comanor and Clark (2000) did find growth rates of younger $Y$. brevifolia to be greater than those of larger individuals at 1 of 3 study sites. And 
we found that the relationship of growth in height to height was slightly, though nonsignificantly, negative for the point-quarter trees and was significantly positive for the smaller and younger belt transect trees (Fig. 2b). However, our sample included a greater range of plant heights than did Comanor and Clark's and showed only a very minor tendency to nonlinear growth. Failure of the Richards function to fit the growth data for $Y$. brevifolia at the Lytle Preserve may be due in part to the relatively short time span over which we measured growth; data spanning a larger portion of $Y$. brevifolia's lifespan might show a more curvilinear growth rate. Nevertheless, the alternative linear growth projection fit the Joshua tree data very well over a substantial range of plant heights (from $0.08 \mathrm{~m}$ to nearly $6 \mathrm{~m}$ ).

\section{ACKNOWLEDGMENTS}

We thank Teri Peterson (Idaho State University Consulting Statistician) and Rob Van Kirk (Idaho State University, Department of Mathematics) for help with statistical estimation and modeling, Brigham Young University for permission to work at Lytle Preserve, Peter Murphy and 2 anonymous reviewers for comments on the manuscript, student researchers who measured Joshua trees, and the NERC Centre for Population Biology (U.K.).

\section{Literature Cited}

Bowers, J.E., AND R.M. Turner. 2001. The influence of climatic variability on local population dynamics of Cercidium microphyllum (foothill paloverde). Oecologia 130:105-113.

Bowers, J.E., R.H. WebB, AND R.J. Rondeau. 1995. Longevity, recruitment and mortality of desert plants in Grand Canyon, Arizona, USA. Journal of Vegetation Science 6:551-564.

Cody, M.L. 2000. Slow motion population dynamics in Mojave Desert perennial plants. Journal of Vegetation Science 11:351-358.

Comanor, P.L., AND W.H. Clark. 2000. Preliminary growth rates and a proposed age-form classification for the Joshua tree, Yucca brevifolia (Agavaceae). Haseltonia 7:37-46.

Drezner, T.D. 2003. Saguaro (Carnegiea gigantea, Cactaceae) age-height relationships and growth: the devel- opment of a general growth curve. American Journal of Botany 90:911-914.

EBERT, T.A. 1999. Plant and animal populations: methods in demography. Academic Press, San Diego, CA. 312 pp.

Goldberg, D.E., And R.M. Turner. 1986. Vegetation change and plant demography in permanent plots in the Sonoran desert. Ecology 67:695-712.

Humphrey, R.R., AND A.B. Humphrey. 1990. Idria columnaris: age determined by growth rate. Desert Plants 10:51-54.

LEE, A.K. 1963. The adaptations to arid environments of woodrats of the genus Neotoma. University of California Publications in Zoology 64:57-96. University of California Press, Berkeley.

McKelvey, S.D. 1935. Notes on Yucca. Journal of the Arnold Arboretum 16:268-271.

Phillips, E.A., K.K. Page, and S.D. Knapp. 1980. Vegetational characteristics of two stands of Joshua tree woodland. Madrono 27:43-47.

Pierson, E.A., And R.M. Turner. 1998. An eighty-five year study of saguaro (Carnegiea gigantea) demography. Ecology 79:2676-2693.

Rasmuson, K.E., J.E. Anderson, and N. Huntly. 1994. Coordination of branch orientation and photosynthetic physiology in the Joshua tree (Yucca brevifolia). Great Basin Naturalist 54:204-211.

Rowlands, P.G. 1978. The vegetation dynamics of the Joshua tree (Yucca brevifolia Engelm.) in the southwestern United States of America. Doctoral dissertation, University of California Riverside, Riverside.

Shreve, F. 1910. The rate of establishment of the giant cactus. Plant World 13:235-240.

Smith, S.D., T.L. Hartsock, AND P.S. Nobel. 1983. Ecophysiology of Yucca brevifolia, an arborescent monocot of the Mojave Desert. Oecologia 60:10-17.

Steenbergh, W.F., AND C.H. Lowe. 1977. Ecology of the saguaro II: reproduction, germination, establishment, growth, and survival of the young plant. National Park Service Monograph Series, Number 8. National Park Service, Washington, DC.

. 1983. Ecology of the saguaro III: growth and demography. National Park Service Monograph Series, No. 17. National Park Service, Washington, DC.

TuRnER, R.M. 1990. Long-term vegetation change at a fully protected Sonoran Desert site. Ecology 71: 464-477.

Webber, J.M. 1953. Yuccas of the Southwest. Agricultural Monographs 17, United States Department of Agriculture.

Wondzell, S., AND J. LudWIG. 1995. Community dynamics of desert grasslands: influences of climate, landforms, and soils. Journal of Vegetation Science 6:377-390.

Received 16 March 2004 Accepted 14 June 2005 